\title{
Cloud Simulations in Response to Turbulence Parameterizations in the GISS Model E GCM
}

\author{
MAO-SUNG YAO* \\ NASA Goddard Institute for Space Studies, and Sigma Space Partners LLC, New York, New York
}

Ye CHENG

NASA Goddard Institute for Space Studies, and Center for Climate Systems Research, Columbia University, New York, New York

(Manuscript received 20 July 2011, in final form 6 January 2012)

\begin{abstract}
The response of cloud simulations to turbulence parameterizations is studied systematically using the GISS general circulation model (GCM) E2 employed in the Intergovernmental Panel on Climate Change's (IPCC) Fifth Assessment Report (AR5). Without the turbulence parameterization, the relative humidity (RH) and the low cloud cover peak unrealistically close to the surface; with the dry convection or with only the local turbulence parameterization, these two quantities improve their vertical structures, but the vertical transport of water vapor is still weak in the planetary boundary layers (PBLs); with both local and nonlocal turbulence parameterizations, the RH and low cloud cover have better vertical structures in all latitudes due to more significant vertical transport of water vapor in the PBL. The study also compares the cloud and radiation climatologies obtained from an experiment using a newer version of turbulence parameterization being developed at GISS with those obtained from the AR5 version. This newer scheme differs from the AR5 version in computing nonlocal transports, turbulent length scale, and PBL height and shows significant improvements in cloud and radiation simulations, especially over the subtropical eastern oceans and the southern oceans. The diagnosed PBL heights appear to correlate well with the low cloud distribution over oceans. This suggests that a cloudproducing scheme needs to be constructed in a framework that also takes the turbulence into consideration.
\end{abstract}

\section{Introduction}

Cloud is one of the major uncertain quantities in determining the atmospheric greenhouse warming (e.g., Cess et al. 1990; Yao and Del Genio 1999; Bony and Dufresne 2005) owing to its role of regulating the radiative heating through its albedo effect, which tends to cool the atmosphere-surface, and through its greenhouse effect, which traps the longwave (LW) radiation and tends to warm the atmosphere-surface. The difficulties in the cloud simulations are not only due to coarse model resolutions and imperfect treatments of cloud physics but also its complicated interactions with

* Current affiliation: Trinnovim LLC, New York, New York.

Corresponding author address: Mao-Sung Yao, NASA Goddard Institute for Space Studies, and Trinnovim LLC, 2880 Broadway, New York, NY 10025.

E-mail: mao-sung.yao@nasa.gov other physics, especially turbulence (e.g., Grenier and Bretherton 2001).

Turbulence effectively transfers heat, moisture, and momentum between the surface and the lower atmosphere, and modifies the atmospheric stability and vertical distributions of these quantities. Moist convection and cloud formation are strongly influenced by this process. The treatments of cloud-topped boundary layers have significant effects on the simulations of marine stratocumulus (e.g., Park and Bretherton 2009; Lock et al. 2000).

In earlier GCMs, dry convective adjustment was applied to perform the role of turbulence (e.g., Hansen et al. 1983). However, it is apparently overly simplified and, as shown later, cannot fully substitute for an explicit turbulence parameterization.

In the earlier attempts of parameterizing the turbulence, the fluxes of heat, moisture, and momentum are down the local gradient of the respective mean field. But this "local" approach still cannot sufficiently transfer these quantities. To more effectively transfer these quantities vertically, a diffusion term and a countergradient 
transport term were included in later parameterizations of turbulence (e.g., Troen and Mahrt 1986; Holtslag and Moeng 1991; Holtslag and Boville 1993). It has been emphasized that the nonlocality is included in both the proposed diffusivity, via the surface forcing and the boundary layer depth, and the additional countergradient term (Large et al. 1994, p. 386).

In this study, we use the Goddard Institute for Space Studies (GISS) Model E2 GCM employed in the Intergovernmental Panel on Climate Change (IPCC) Fifth Assessment Report (AR5) (G. A. Schmidt et al. 2012, unpublished manuscript) to systematically identify the influence of turbulence parameterization on the cloud simulations. We also present a newer version of the turbulence parameterization being developed at GISS and compare the cloud and radiation climatologies obtained with those obtained from the AR5 version.

In section 2, we describe the models used. We show the experiments conducted in section 3 and the results in section 4. A summary and conclusions are given in section 5 .

\section{The models}

Except for the parameters for computing the threshold relative humidity $\mathrm{RH}\left(U_{\mathrm{oo}}\right)$, a minimum $\mathrm{RH}$ for cloud formation, and the limiting autoconversion rate associated with upward motion, we use the same GISS Model E2 GCM employed in the AR5 experiments with climatological (monthly varying) sea surface temperatures (SSTs) and sea ice coverage (Rayner et al. 2003) averaged from 1975 to 1984 . The model has 40 layers in the vertical and $2^{\circ}$ (latitude) $\times 2.5^{\circ}$ (longitude) horizontal resolution; the physical time step for cloud and turbulence computations is $30 \mathrm{~min}$.

\section{a. Cloud and moist convection parameterization}

The clouds in the model include stratiform clouds and convective clouds. The cloud and moist convection parameterization used in AR5 is an improvement on the version used in the IPCC Fourth Assessment Report (AR4) (Schmidt et al. 2006).

Numerous improvements have been implemented in the AR5 version. For the moist convection (MC), we calculate entrainment rates and cumulus updraft speeds interactively (Del Genio et al. 2007). MC transports the convective condensate vertically. Downdrafts can originate from multiple layers and are allowed to detrain at lower layers, and drop below the cloud base only if they are negatively buoyant. The downdrafts also include entrainment and detrainment. The cumulus momentum mixing is affected by the cumulus pressure gradient. The downdraft mass fluxes are used to calculate a gustiness correction to surface fluxes. The convective cloud cover depends on the cumulus updraft speed. The rain evaporation in downdrafts is limited to the extent of saturating the downdraft, and one hour is used for the convective adjustment time among other minor changes.

For the stratiform clouds, instead of specifying the $U_{\text {oo, }}$, we calculate it and use two parameters $-U_{a}$ and $U_{b}$ - to achieve radiative balance and a better cloud climatology. We set $U_{\mathrm{oo}}=U_{a} /\left[U_{a}+\left(1-U_{a}\right) \Delta p / 35\right]$, where $\Delta p$ is the layer pressure depth and $U_{\mathrm{oo}}$ is further reduced if there is upward motion. However, in the moist convective area and in the PBL, we set $U_{\text {oo }}=$ $1-2 U_{b}\left[\sigma / q^{*}(T, p)\right]$, where $\sigma$ represents the subgrid variability of humidity (Siebesma et al. 2003), $q^{*}$ is the saturation specific humidity, and $T$ is temperature; $U_{a}$ primarily affects the higher clouds above the $850-\mathrm{mb}$ $(\mathrm{hPa})$ level and $U_{b}$ mainly affects the lower clouds below the $850-\mathrm{mb}$ level. The ice phase is maintained once a cloud forms if $T<0^{\circ} \mathrm{C}$ and the liquid cloud phase is maintained if $T>-4^{\circ} \mathrm{C}$. Partial evaporation of cloud water in unfavorable conditions for cloud formation is allowed, and the optical thickness of precipitation is included. Averaged vertical velocity over one physical time step is used to modify the autoconversion rate. Ice cloud forms if $T<-35^{\circ} \mathrm{C}$, and the Kärcher and Lohmann formula (Kärcher and Lohmann 2002) for computing the saturation vapor pressure below $-35^{\circ} \mathrm{C}$ is used among other minor changes.

\section{b. Turbulence parameterization}

The turbulence parameterization for AR5 experiments is similar to the version used in AR4 experiments (Schmidt et al. 2006). It includes 1) a nonlocal vertical transport scheme for virtual potential temperature, specific humidity, and other scalars following Holtslag and Moeng (1991), inside the PBL and for both stable and unstable stratifications; 2) diagnosis of the nonlocal vertical profile of the turbulent kinetic energy (TKE) according to the large eddy simulation (LES) studies of Moeng and Sullivan (1994) that include the PBL height in the computation, inside the PBL and again for both stable and unstable stratifications; 3) above the PBL, employment of the second-order closure (SOC) scheme of Cheng et al. (2002) that improves several aspects of the standard Mellor-Yamada model (Mellor and Yamada 1982) and in particular, allows mixing at weak turbulence levels; 4) formulation of the turbulence length scale similar to Holtslag and Boville (1993); 5) calculation of the PBL height using the TKE criterion (PBL top is where TKE decreases to $10 \%$ of its surface value), and 6) between the surface and the first GCM layer, integrating the SOC model equations over the subgrid levels, instead of applying the usual interpolation scheme, to 
find the surface velocity, temperature, humidity, among others, which is unique among the GCMs, and is convenient to add more physics and allows coarse vertical resolutions near the surface.

Using $C$ as a general variable for the mean virtual potential temperature, specific humidity, or winds, and $c$ for the respective fluctuating parts, the general equation for computing its vertical flux is

$$
\overline{w c}=-K_{C} \frac{\partial C}{\partial z}+(\overline{w c})_{c g},
$$

where $w$ is the fluctuating part of the vertical velocity, $z$ is the height, and $K_{C}$ is the eddy diffusivity. The first term on the rhs of Eq. (1) contains both the local and nonlocal contributions, and the second term is the nonlocal countergradient contribution to the vertical turbulent flux. Note that $K_{C}$ depends on characteristic bulk properties of the PBL rather than just local properties (see, e.g., Troen and Mahrt 1986; Holtslag and Boville 1993).

To further see the influence of the turbulence parameterizations on the cloud simulations, we conduct experiments using a modified version of the turbulence parameterization being developed at GISS. Both the turbulence scheme in the AR5 and the newer scheme employ the nonlocal model as in Eq. (1) above, but the specific forms of the diffusivities and the countergradient terms, as well as the related turbulence length scales and the PBL height, a critical input to the nonlocal scheme, are quite different. This newer scheme differs from the AR5 version as follows:

1) Nonlocal vertical transport scheme for velocity, virtual potential temperature, specific humidity, and other scalars. Both the AR5 turbulence scheme and the newer scheme employ expression (1), but the diffusivities $K_{C}$ and the counter gradient flux term $(\overline{w c})_{c g}$ are modeled differently.

The AR5 scheme follows Holtslag and Moeng (1991). The heat diffusivity, $K_{C}$, and the countergradient flux, $(\overline{w c})_{c g}$, are derived from the dynamic equation for $\overline{w c}$, with the third-moment terms (related to the transport and the pressure) parameterized using the LES data; the results are

$$
\begin{aligned}
& K_{C}=0.045 \overline{w^{2}} \tau, \\
& \overline{w^{2}}=\left\{\left[1.6 u_{*}^{2}\left(1-\frac{z}{h}\right)\right]^{3 / 2}+1.2 w_{*}^{3} \frac{z}{h}\left(1-0.9 \frac{z}{h}\right)^{3 / 2}\right\}^{2 / 3},
\end{aligned}
$$

and

$$
(\overline{w c})_{c g}=0.091 \frac{w_{*} \tau}{h}(\overline{w c})_{0},
$$

where $\overline{w^{2}}$ is twice the vertical component of the TKE $e,(\overline{w c})_{0}$ is the value of $\overline{w c}$ at the surface, $\tau=2 e / \varepsilon$ is the turbulence time scale with $\varepsilon$ the dissipation rate of $e, h$ is the PBL height, $u_{*}$ is the friction velocity, and $w_{*}$ is the Deardorff buoyancy velocity scale that also depends on $h$, defined as

$$
w_{*}=\left[g \alpha\left(\overline{w \theta_{v}}\right)_{0} h\right]^{1 / 3},
$$

where $g$ is the gravitational acceleration, $\alpha$ is the thermal expansion coefficient at the surface, and $\theta_{v}$ is the turbulent fluctuation of the virtual potential temperature.

The newer scheme follows Holtslag and Boville (1993), where

$$
\begin{aligned}
K_{C} & =\kappa w_{t} z\left(1-\frac{z}{h}\right)^{2}, \\
(\overline{w c})_{c g} & =7.2 K_{C} \frac{w_{*}(\overline{w c})_{0}}{w_{m}^{2} h},
\end{aligned}
$$

where $\kappa=0.4$ is the von Kármán constant, $w_{m}$ is a velocity scale contributed by both the wind shear and the buoyancy,

$$
w_{m}=\left(u_{*}^{3}+0.6 w_{*}^{3}\right)^{1 / 3},
$$

and $w_{t}=w_{m} / \mathrm{Pr}$ is the velocity scale for mixing of heat or passive scalars, where $\operatorname{Pr}$ is the turbulent Prandtl number; both $w_{m}$ and $w_{t}$ are characteristic of the surface forcing that is exerted to the whole PBL.

2) Formulation of the turbulence length scale $\ell$, defined in

$$
\varepsilon=\frac{(2 e)^{3 / 2}}{B_{1} \ell},
$$

where $B_{1}=19.3$ is a constant determined in Cheng et al. (2002).

The AR5 scheme follows Holtslag and Boville (1993), where

$\frac{1}{\ell}=\frac{1}{\ell_{s}}+\frac{1}{\ell_{0}}$

$\ell_{s}=\kappa z, \quad$ and $\quad \ell_{0}=30+270 \exp (1-z / 1000)(\mathrm{m})$,

where $\ell_{s}$ is the length scale near to the surface and $\ell_{0}$ is the turbulence length scale away from the surface. The newer scheme shows that for $z \geq h$, we use (8) while generalizing (9) as

$$
\ell_{0}=30+\max (0.3 h-30,0) \exp (1-z / h)(\mathrm{m}) ;
$$


for $z<h$, we use the formula obtained from the large eddy simulation data by Nakanishi (2001), as follows:

$$
\frac{1}{\ell}=\frac{1}{\ell_{s}}+\frac{1}{\ell_{0}}+\frac{1}{\ell_{b}}
$$

where $\ell_{s}, \ell_{0}$, and $\ell_{b}$ are the modified surface length scale, the length scale away from the surface, and the Deardorff buoyancy length scale, respectively; the expressions are formulated to match the LES data, and are lengthy so we refer the interested readers to Nakanishi (2001) for more details. The buoyancy length scale has a dependence on the TKE; the latter is parameterized using the LES data (Moeng and Sullivan 1994). The TKE is also used in the formulation of the diffusivities in the local SOC model in both the AR5 scheme and in the newer scheme (Cheng et al. 2002).

3) Calculation of the PBL height.

The AR5 scheme uses the "TKE criterion," by which the PBL top is where the TKE decreases to $10 \%$ of its surface value.

The newer scheme uses the "Richardson number criterion" according to Troen and Mahrt (1986) and Holtslag and Boville (1993), in which the PBL height $h$ is determined by

$$
h=\frac{\operatorname{Ri}_{\mathrm{cr}}\left[U(h)^{2}+V(h)^{2}\right]}{g \alpha\left[\Theta_{v}(h)-\Theta_{s}\right]},
$$

where $\mathrm{Ri}_{\text {cr }}(=0.5)$ is a critical bulk Richardson number, $U(h)$ and $V(h)$ are the horizontal mean wind components, $\Theta_{v}$ is the mean virtual potential temperature, and $\Theta_{s}$ is a temperature near the surface that may relate to the surface virtual heat flux $\left(\overline{w \theta_{v}}\right)_{0}$ depending on the stability condition, defined as

$$
\Theta_{s}=\left\{\begin{array}{cc}
\Theta_{v}\left(z_{s}\right)+8.5 \frac{\left(\overline{w \theta_{v}}\right)_{0}}{w_{m}}, & \left(\overline{w \theta_{v}}\right)_{0}>0 \\
\Theta_{v}\left(z_{s}\right), & \left(\overline{w \theta_{v}}\right)_{0} \leq 0
\end{array}\right\},
$$

where $z_{s}=10 \mathrm{~m}$ is the surface layer height. For more details, see appendix A of Holtslag and Boville (1993). We will further discuss the impacts of the new turbulence scheme and the physical reasons behind them in section 4 .

In this work we will not include explicit treatments of PBL-top entrainment and radiative-cooling-driven turbulence that are being developed at GISS, but we have cloud-top entrainment in the parameterization of largescale clouds (Del Genio et al. 1996). Explicit treatments of PBL-top entrainment and radiative cooling effect will be included in further development of the turbulence parameterization. Despite this, as shown in the results, the newer version of the turbulence parameterization significantly improves the simulations of cloud and radiation.

In recent turbulence parameterizations, the moist conserved variables, the liquid water potential temperature $\ominus_{l}$, and the total water mixing ratio $Q_{t}$ are used for treating both dry and cloudy layers (Lock et al. 2000; Grenier and Bretherton 2001; Bretherton and Park 2009). But the GISS ModelE uses the potential temperature and the specific humidity as prognostic variables, and the computations of moist convection and large-scale clouds are handled separately from the turbulence parameterization. Therefore, for consistency and simplicity, in this study we use virtual potential temperature and specific humidity as prognostic variables, while we are working toward using $\ominus_{l}$ and $Q_{t}$ in the model.

\section{Experiments}

We use the GISS Model E2 GCM described above as the control and then conduct several experiments with changes in the parameterization of turbulence, as described below:

1) Experiment CONTROL: the control run as described above.

2) Experiment NO-TURB: an experiment without any parameterization of turbulence.

3) Experiment DRY-CONV: an experiment with dry convection to represent the turbulence process. In the process of dry convection, vertical mixing of heat, moisture, and momentum will occur to restore the static stability if the temperature profile is static unstable.

4) Experiment LOCAL: an experiment with only the local parameterization of turbulence.

5) Experiment NEW-TURB: an experiment that includes both local and nonlocal parameterizations of turbulence, but with certain changes from CONTROL as described in section 2 .

We integrate CONTROL and NEW-TURB for 5 yr but only $1 \mathrm{yr}$ for NO-TURB, DRY-CONV, and LOCAL, since their effects are clearly seen in one year of integration and they are not intended for comparison of climatologies. CONTROL and NEW-TURB are in radiative balance by properly choosing the parameters $U_{a}$ and $U_{b}: U_{a}=0.7$ in CONTROL and 0.72 in NEW-TURB and $U_{b}=1.96$ in both CONTROL and NEW-TURB. NO-TURB, DRY-CONV, and LOCAL use the same values for $U_{a}$ and $U_{b}$ as in CONTROL and are not tuned to radiative balance. 
TABLE 1 . Selected global mean and annual mean climate variables, and $U_{a}$ and $U_{b}$. The planetary albedo and cloud cover are in percent, radiative fluxes are in watts per meter squared, and the precipitation is in millimeters per day.

\begin{tabular}{|c|c|c|c|c|c|}
\hline & CONTROL & NO-TURB & DRY-CONV & LOCAL & NEW-TURB \\
\hline Planetary albedo & 29.610 & 26.182 & 25.680 & 27.554 & 30.476 \\
\hline Solar absorption TOA & 240.54 & 252.25 & 253.97 & 247.57 & 237.58 \\
\hline Net LW TOA & -240.27 & -241.64 & -240.38 & -238.00 & -237.55 \\
\hline Net heat at surface & 0.27 & 10.84 & 13.79 & 9.79 & 0.06 \\
\hline Precipitation & 3.171 & 2.643 & 2.925 & 3.066 & 3.099 \\
\hline Total cloud & 60.54 & 57.63 & 55.06 & 59.99 & 64.96 \\
\hline High cloud & 31.0 & 31.6 & 32.5 & 34.4 & 31.8 \\
\hline Middle cloud & 15.4 & 16.2 & 15.8 & 16.8 & 16.1 \\
\hline Low cloud & 43.0 & 39.9 & 32.7 & 39.5 & 46.9 \\
\hline$U_{a}$ & 0.70 & 0.70 & 0.70 & 0.70 & 0.72 \\
\hline$U_{b}$ & 1.96 & 1.96 & 1.96 & 1.96 & 1.96 \\
\hline
\end{tabular}

\section{Results and analyses}

Here we will compare and discuss the results obtained from each experiment described in section 3 with those obtained from CONTROL. Table 1 shows some climate variables from these experiments. Note that NO-TURB, DRY-CONV, and LOCAL are not tuned to radiative balance, and they have very low planetary albedo partially because of smaller low cloud amounts.
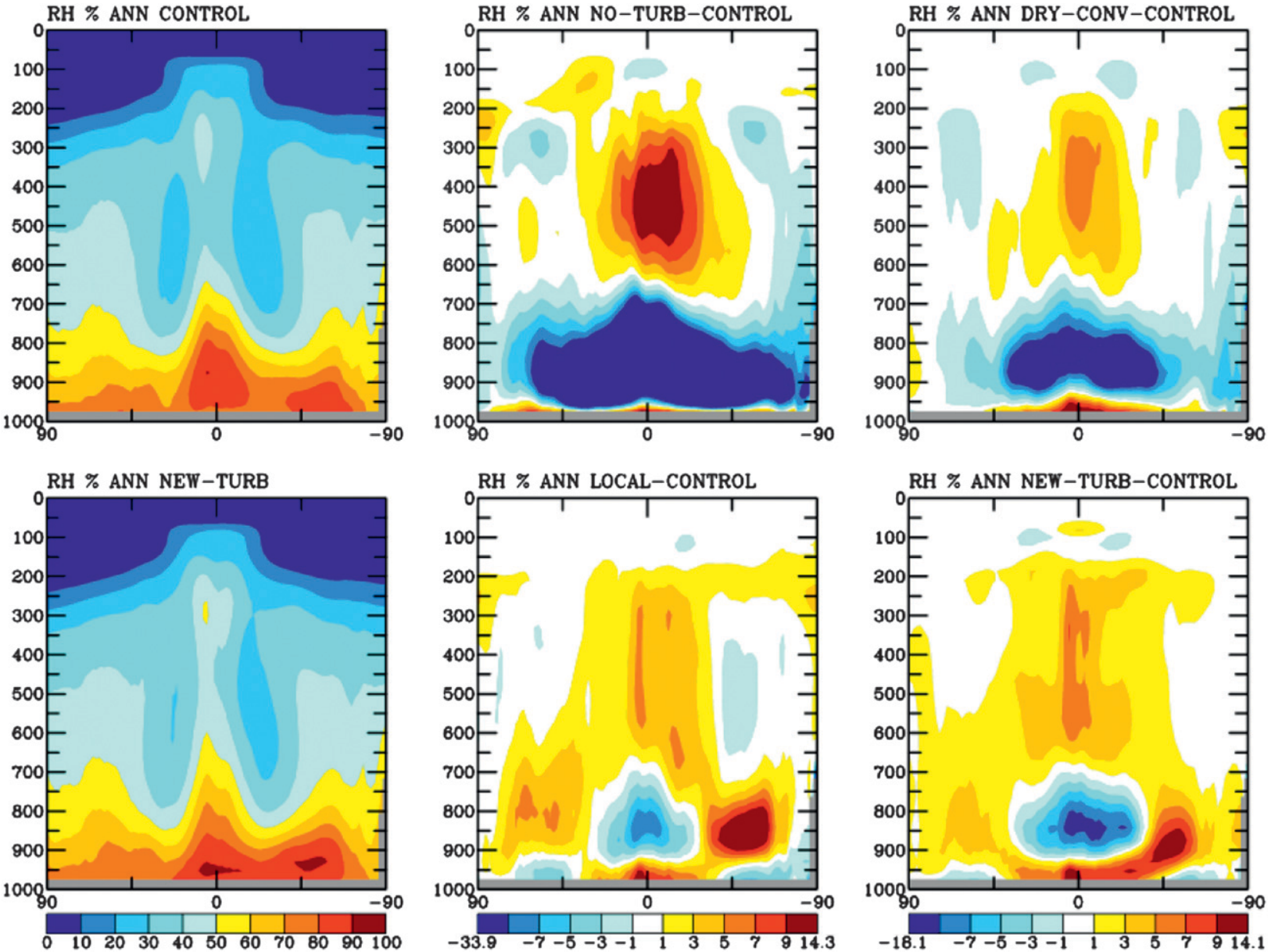

FIG. 1. Annual mean and zonal mean of RH (\%) of (top) CONTROL, NO-TURB-CONTROL, and DRY-CONV-CONTROL and (bottom) NEW-TURB, LOCAL-CONTROL, and NEW-TURB-CONTROL. 
TOTAL CLOUD \% ANN CONTROL

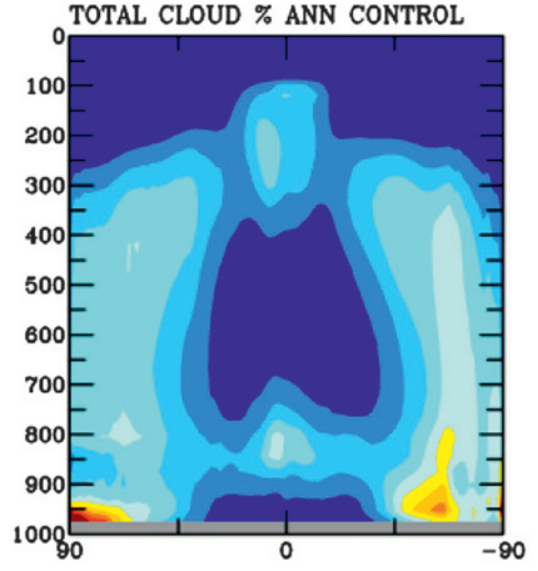

TOTAL CLOUD \% ANN NEW-TURB

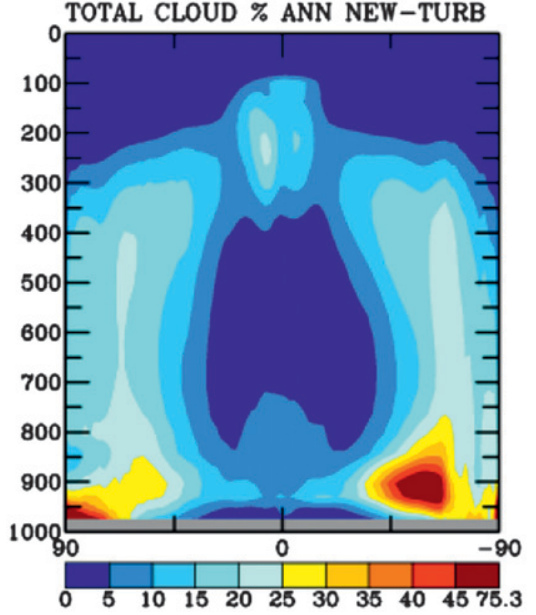

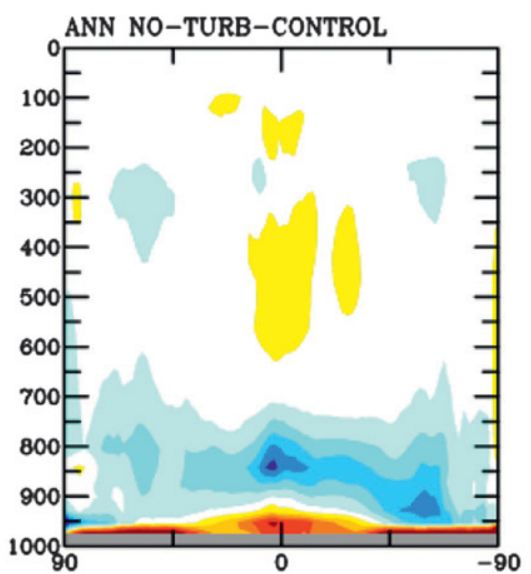

ANN LOCAL-CONTROL

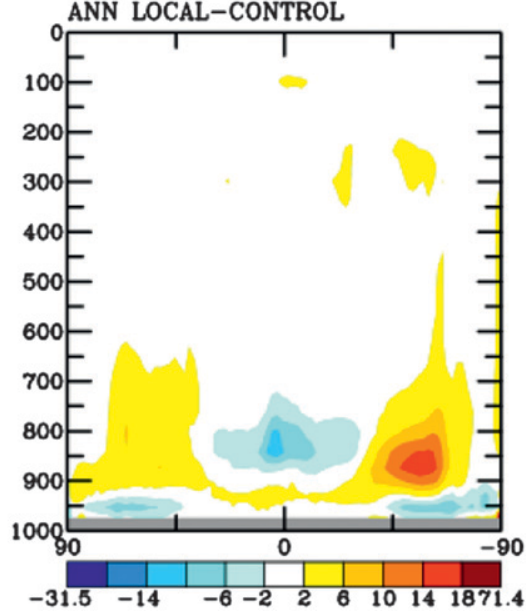

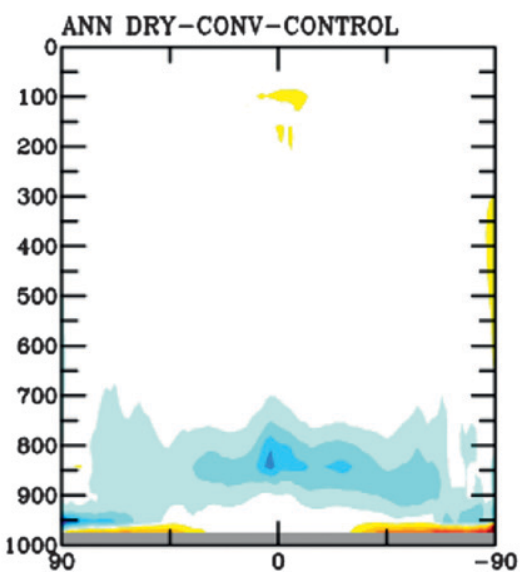

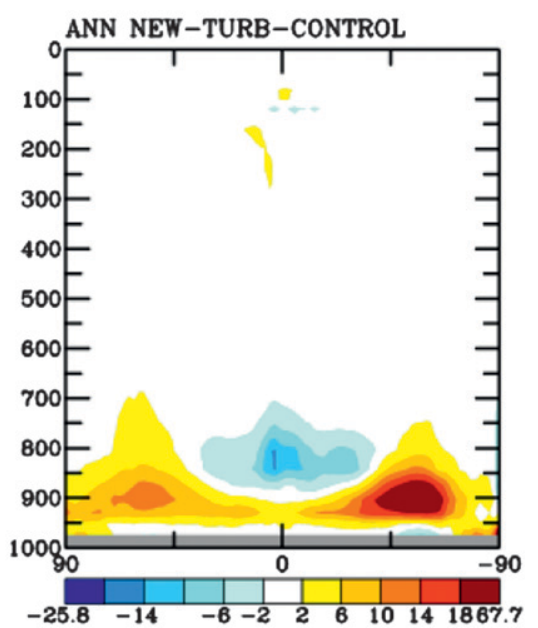

FIG. 2. As in Fig. 1, but for total cloud cover (\%).

\section{a. Experiments identifying the turbulent effects}

The experiment without any turbulence parameterization has $\mathrm{RH}$ and low cloud cover peaking right above the surface (Figs. 1 and 2), which is highly unrealistic since RH peaks at the top of a well-mixed PBL (Holtslag and Boville 1993). The temperature structure in the lower atmosphere is statically unstable (not shown), suggesting some vertical mixing processes are needed.

When the dry convection is employed, the moisture is sharply reduced near the surface but the strong vertical transport is mainly near $900 \mathrm{mb}$ and below (Fig. 3). As a result, the humidity and low cloud cover below $800 \mathrm{mb}$ are still smaller than those of CONTROL, although the vertical distribution of $\mathrm{RH}$ and low cloud cover are clearly better than the case of NO-TURB (Figs. 1 and 2).

When the local parameterization of turbulence is applied, the vertical transports of humidity are still insufficient above $900 \mathrm{mb}$ in the tropics compared with CONTROL, but they are similar in magnitude in the middle and higher latitudes (Fig. 3). Consequently, the RH and low cloud cover also show similar changes in the vertical structures (Figs. 1 and 2).

The larger RH and cloud cover in the upper troposphere in the tropics in NO-TURB and DRY-CONV are in part due to weaker deep moist convections that dry the atmosphere to a lesser degree because of weaker subgrid scale compensating subsidence warming and drying in these cases although the shallow convections are stronger (not shown), since the atmospheric structure is less stable in the lower atmosphere because of less turbulent transports.

\section{b. Comparison of the newer turbulence scheme with the control}

We now compare the climatologies of cloud and radiation obtained from NEW-TURB and CONTROL in greater detail. We compare some global mean and annual mean quantities in Table 1 . These values look similar between NEW-TURB and CONTROL, although 

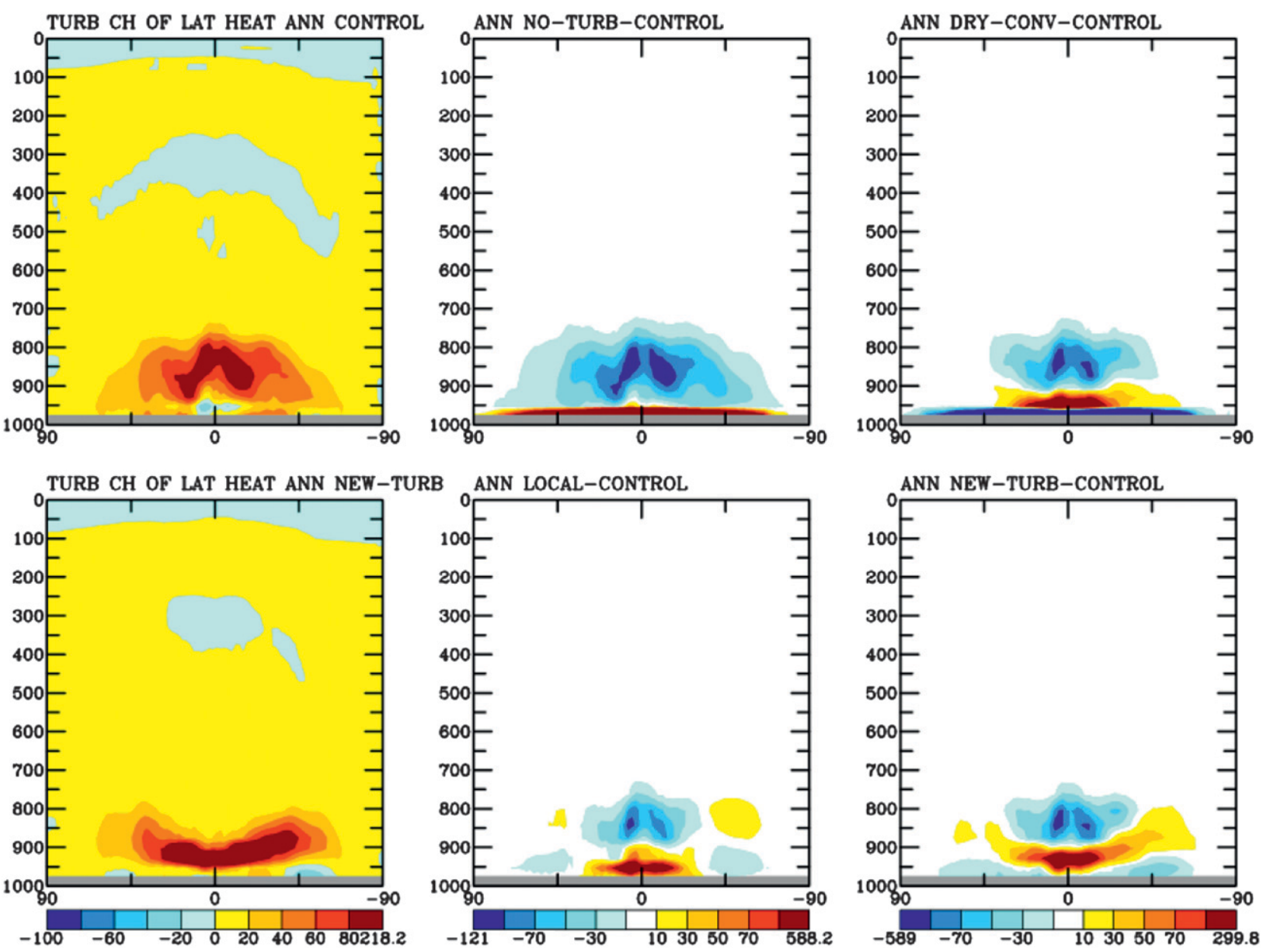

FIG. 3. As in Fig. 1, but for turbulent changes of latent heat $\left(10^{-2} \mathrm{~W} \mathrm{mb}^{-1} \mathrm{~m}^{-2}\right)$.

NEW-TURB has a higher planetary albedo because of a higher low cloud amount.

Figure 4 compares their geographical distributions of total cloud with observations from the International Satellite Cloud Climatology Project (ISCCP) (Rossow et al. 2002) for January and July. Generally speaking, NEW-TURB agrees with observations better, especially over subtropical eastern oceans, where fewer clouds are simulated in most climate models (e.g., Weare et al.1995; Hannay et al. 2009). Further analyses indicate the differences of the total cloud are mainly due to low cloud simulation (not shown). High clouds associated with deep convections may contribute to the differences in the tropics (not shown). The larger cloud amounts in higher latitudes and smaller cloud amounts in tropical oceans obtained by NEW-TURB are closely related to the RH in the PBL (Fig. 5). Note that Fig. 5 is for the 850-mb level and that over the subtropical eastern oceans, the RH at $700 \mathrm{mb}$ (not shown) is a better level to compare. This is plausibly related to the vertical turbulent fluxes of moisture and the diagnosed PBL height (see more discussion below). But the shallow moist convection (Fig. 6) may also play an important role, notably over the subtropical eastern oceans. The strength of shallow convection is closely related to the stability in the lower PBL, which is affected by the turbulent fluxes. The increased shallow convective cloud cover is small (not shown), but it moistens the atmosphere at the convective cloud-top level and helps the formation of stratiform clouds there. The shallow convection also intensifies the vertical turbulent transport of heat, moisture, and momentum, and as a result deepens the cloudy boundary layer (Tiedtke et al. 1988). Note that we do not have a separate parameterization for the shallow convection as in some GCMs (e.g., Park and Bretherton 2009).

The differences in cloud simulations between NEWTURB and CONTROL clearly will have a large impact on the solar absorption (Fig. 7). In general, NEW-TURB produces better solar absorption, especially over the 


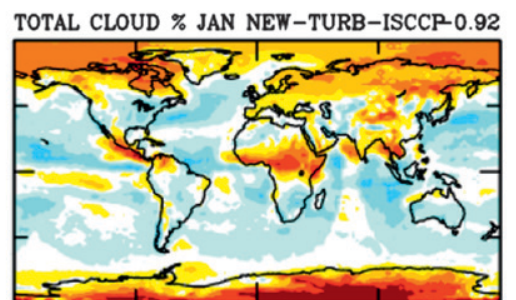

TOTAL CLOUD \% JUL NEW-TURB-ISCCP 3.91

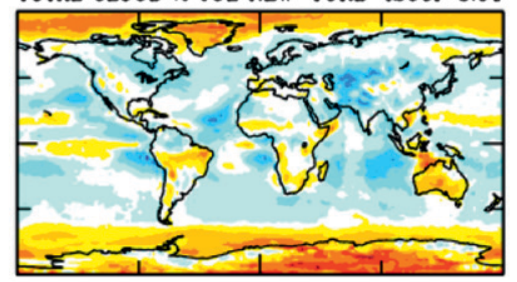

TOTAL CLOUD \% JAN CONTROL-ISCCP -4.89

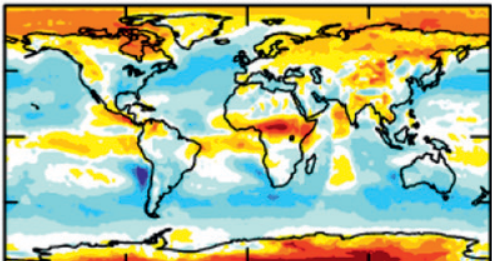

TOTAL CLOUD \% JUL CONTROL-ISCCP -8.49

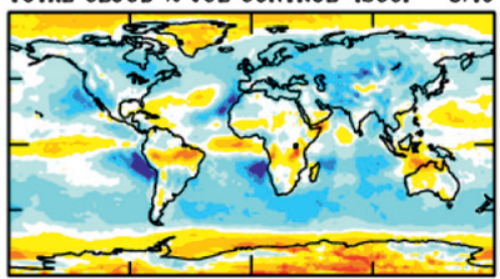

TOTAL CLOUD JAN NEW-TURB-CONTROL3.97

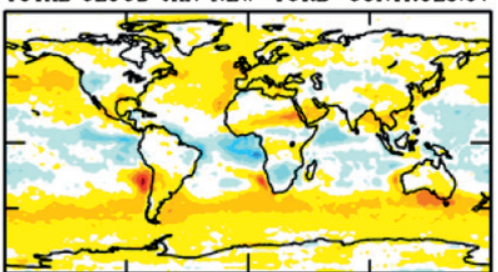

TOTAL CLOUD JUL NEW-TURB-CONTROL4.58

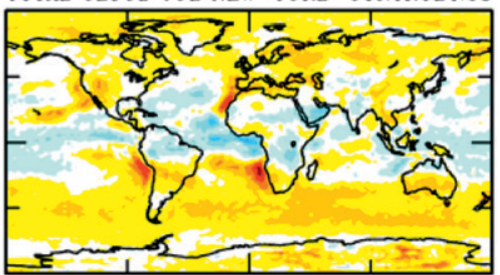

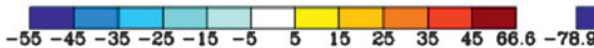
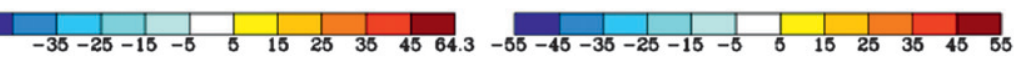

FIG. 4. Total cloud cover (\%) of NEW-TURB-ISCCP observation, CONTROL-ISCCP observation, and NEW-TURB-CONTROL for (top) January and (bottom) July.

subtropical eastern oceans and the southern oceans. But the solar absorption over the subtropical eastern oceans is still too large compared with the observation. More complete treatments of cloud-top-driven turbulence may be needed to reduce this quantity. The solar absorption is generally too strong over the southern oceans in climate simulations, which may affect the cloud feedback in GCMs (Trenberth and Fasullo 2010). The solar absorption over the Arctic oceans in July is apparently too large in both NEW-TURB and CONTROL. This excessive solar absorption helps melt the sea ice in July and is designed to prevent excessive growth of sea ice in the coupled runs in which the sea surface temperatures are predicted. However, this is only a temporary fix until a better sea ice transport scheme and stronger poleward heat transports can avoid the excessive sea ice growth in coupled runs.

To find out the differences in the turbulent processes between NEW_TURB and CONTROL that can, at least qualitatively, explain the differences in the simulations of cloud and radiation, we show the boundary layer heights $h$ in Fig. 8, in which $h$ obtained in NEWTURB is higher over land and over oceans in middle and higher latitudes but is lower over oceans in the tropics. However, $h$ is higher over subtropical eastern oceans in NEW-TURB than CONTROL. So, except for over land, the differences in $h$ correlate with the differences
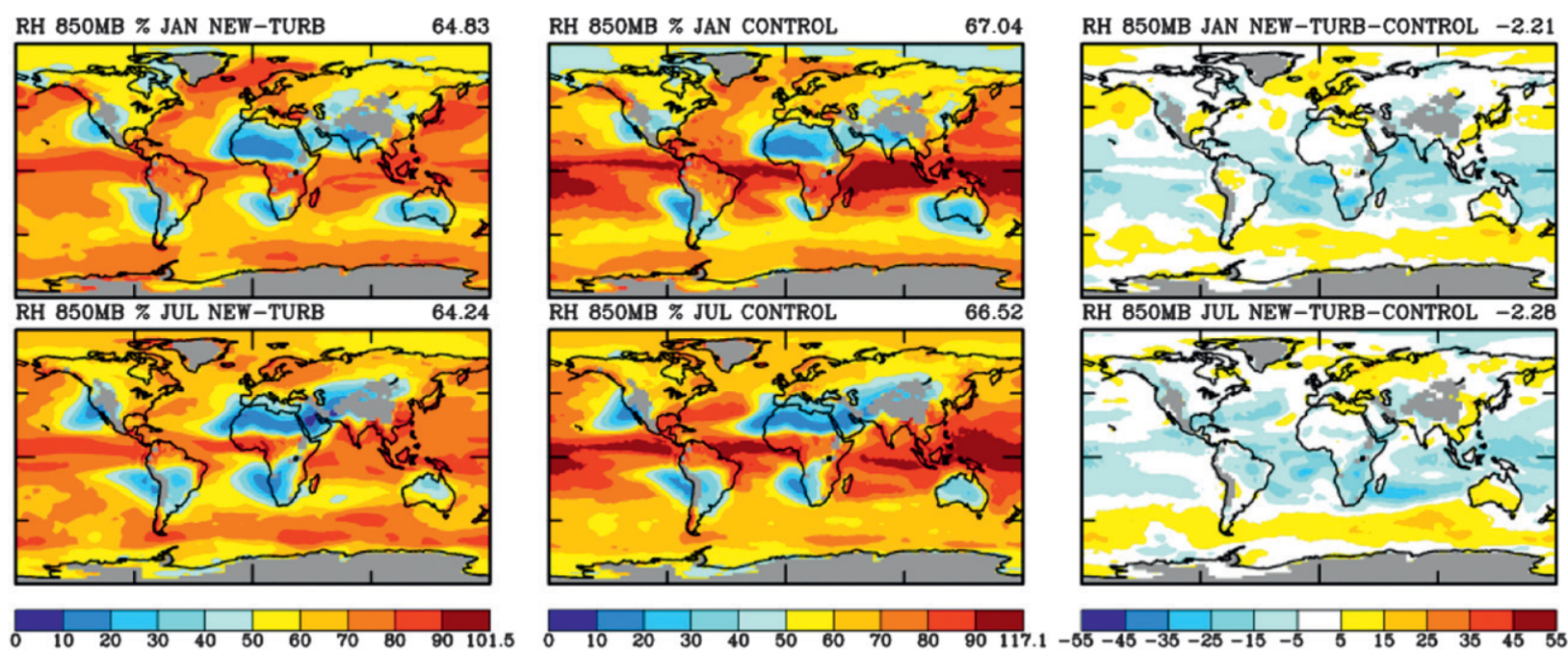

FIG. 5. 850-mb RH (\%) of NEW-TURB, CONTROL, and NEW-TURB-CONTROL for (top) January and (bottom) July. 

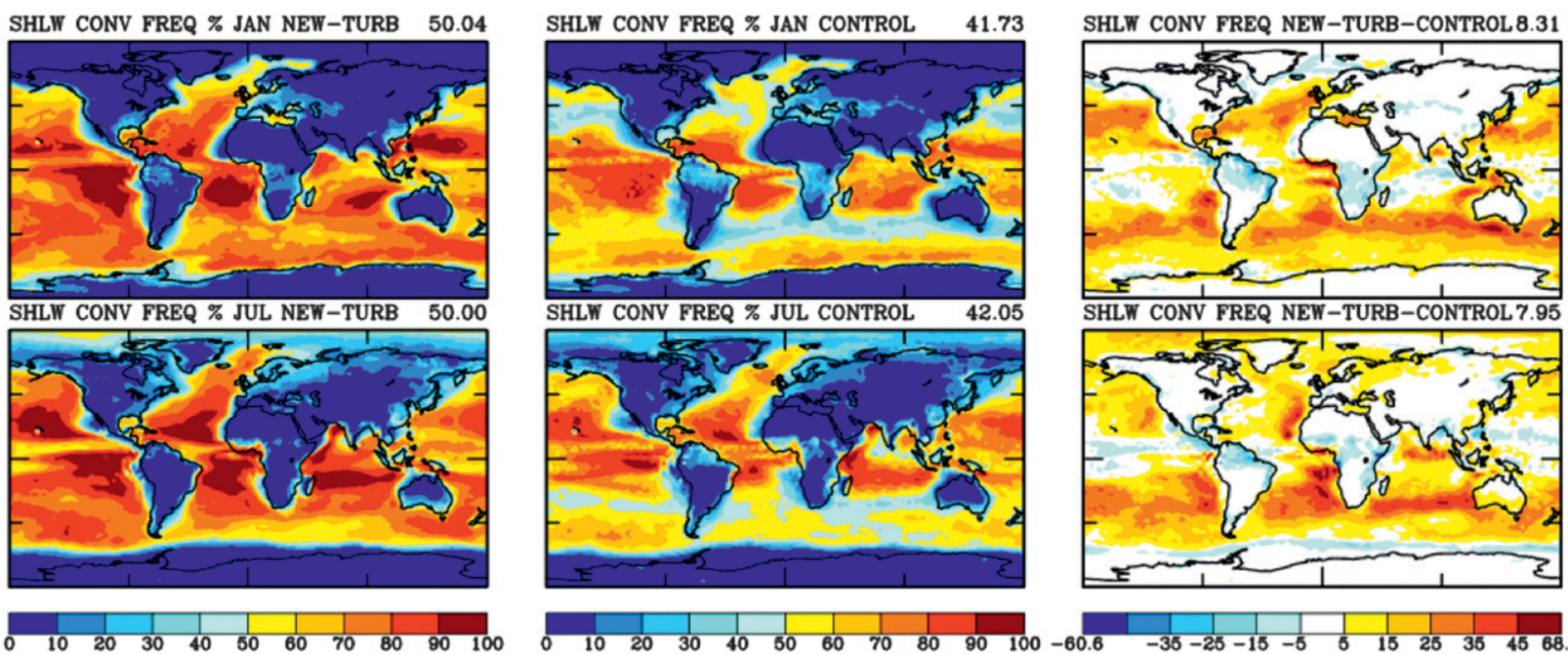

FIG. 6. As in Fig. 5, but for shallow convective frequency (\%).

in cloud simulations quite well. Higher $h$ tends to transfer moisture higher and produces higher RH and cloud cover. The differences in $h$ are clearly affected by the different methods of determining the PBL top between NEW-TURB and CONTROL. A test experiment with NEW-TURB using the method of calculating the PBL top as in CONTROL further confirms this point (not shown). Nevertheless, larger $h$ tends to produces larger turbulent fluxes [see Eqs. (1)-(5)] and has significant effects on RH and the low cloud amount. Over land, this relationship is not clear because of complicated interactions with the surface physics. The boundary heights over midlatitude and high-latitude oceans seem to be on the high side, but they appear to be similar in magnitude to the observations of von Engeln and Teixeira (2012, manuscript submitted to J. Climate). The other two main differences in nonlocal vertical transport and length-scale formulation between NEW-TURB and CONTROL appear to have only produced small improvements in the results (not shown).

Since the precipitation is associated with the cloud processes, we compare the precipitation climatologies with observations of the Global Precipitation Climatology Project (GPCP) (Huffman et al. 1997) in Fig. 9. Both NEW-TURB and CONTROL produce the precipitation reasonably well, although NEW-TURB produces weaker precipitation than what is observed over the Amazon area in July.
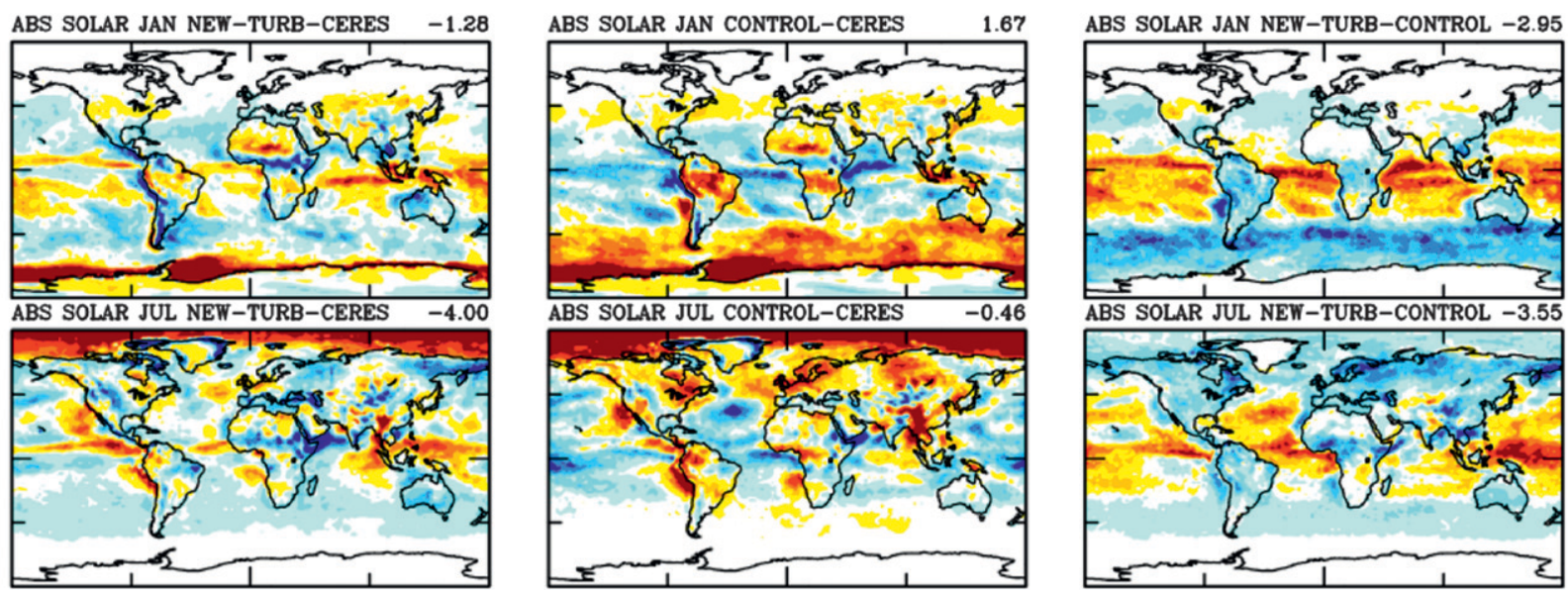

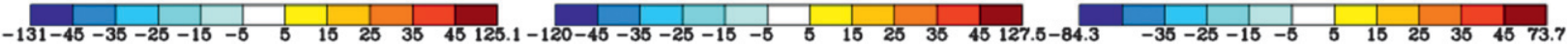

FIG. 7. Solar absorption at top of atmosphere (TOA) $\left(\mathrm{W} \mathrm{m}^{-2}\right)$ of NEW-TURB minus the Clouds and the Earth's Radiant Energy System (CERES) observation, CONTROL-CERES observation, and NEW-TURB-CONTROL for (top) January and (bottom) July. 

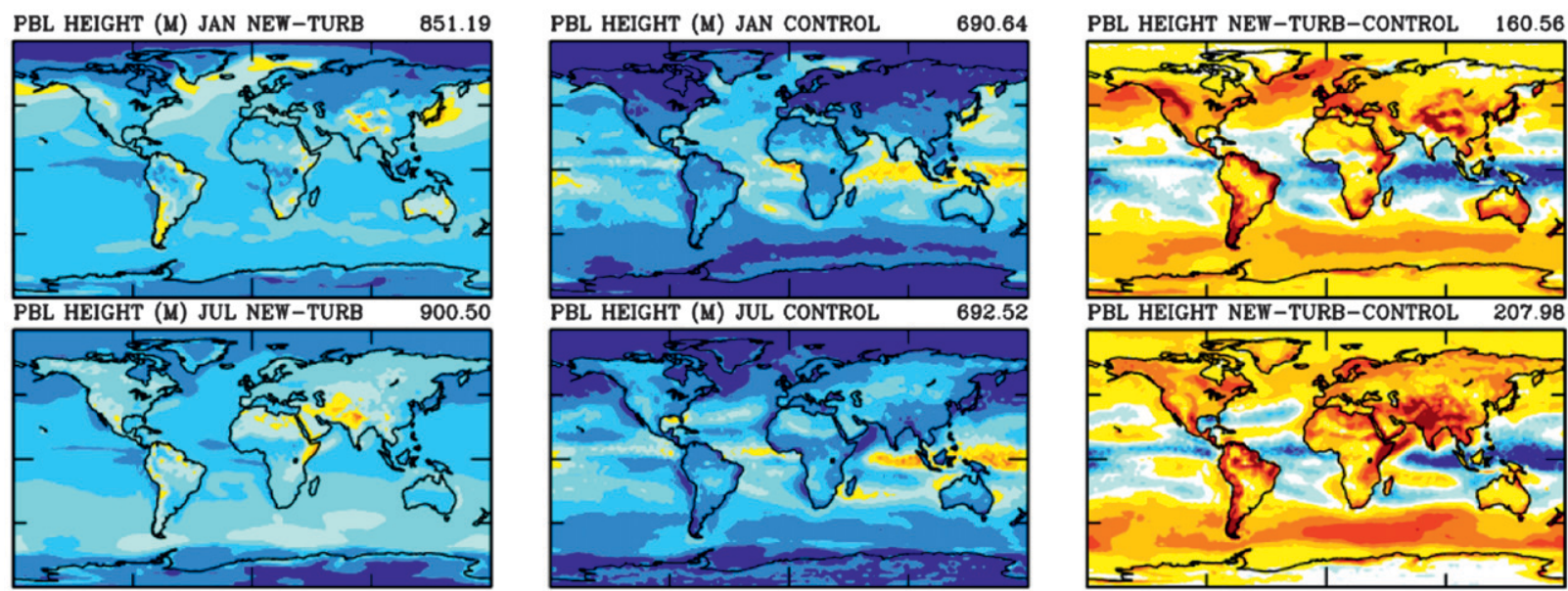

3006009001200150018002100240027003000

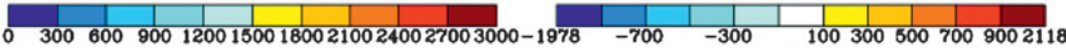

FIG. 8. As in Fig. 5, but for PBL height (m).

The latitude-pressure cross sections of differences in $\mathrm{RH}$, total cloud cover, and turbulent latent heat between NEW-TURB and CONTROL are shown in Figs. 1-3. NEW-TURB vertically transports heat and moisture not as deep as in CONTROL in the tropics, but deeper in mid- and higher latitudes. This is likely related to the PBL height calculated. The RH and low cloud cover have vertical distributions reflecting these differences in the turbulent transports. This may also contribute to the differences in their cloud and radiation climatologies.

We also note that NEW-TURB produces more realistic diurnal variations of convective precipitation. Over land in the tropics, the convective precipitation peaks around $1500 \mathrm{LT}$ instead of around $1200 \mathrm{LT}$ in the AR5 version (not shown). Better interactions between the moist convection and PBL are important for simulating the diurnal variations of convective precipitation (Rio et al. 2009). Further analyses are needed for this aspect of cloud simulation and will be a subject for future studies.

\section{Summary and conclusions}

Using the GISS Model E2 GCM employed in AR5 experiments, we have carried out a series of experiments to explore the impact of turbulence parameterizations on the cloud simulations. Without the turbulence

PRECIPITATION MM/DAY JAN NEW-TURB3.05

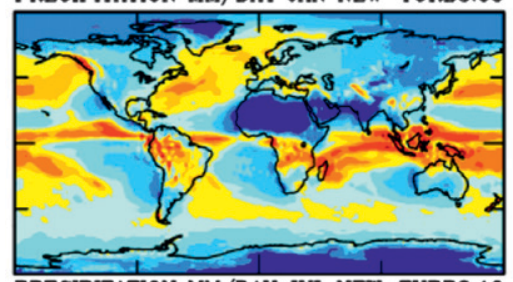

PRECIPITATION MM/DAY JUL NEW-TURB3.19
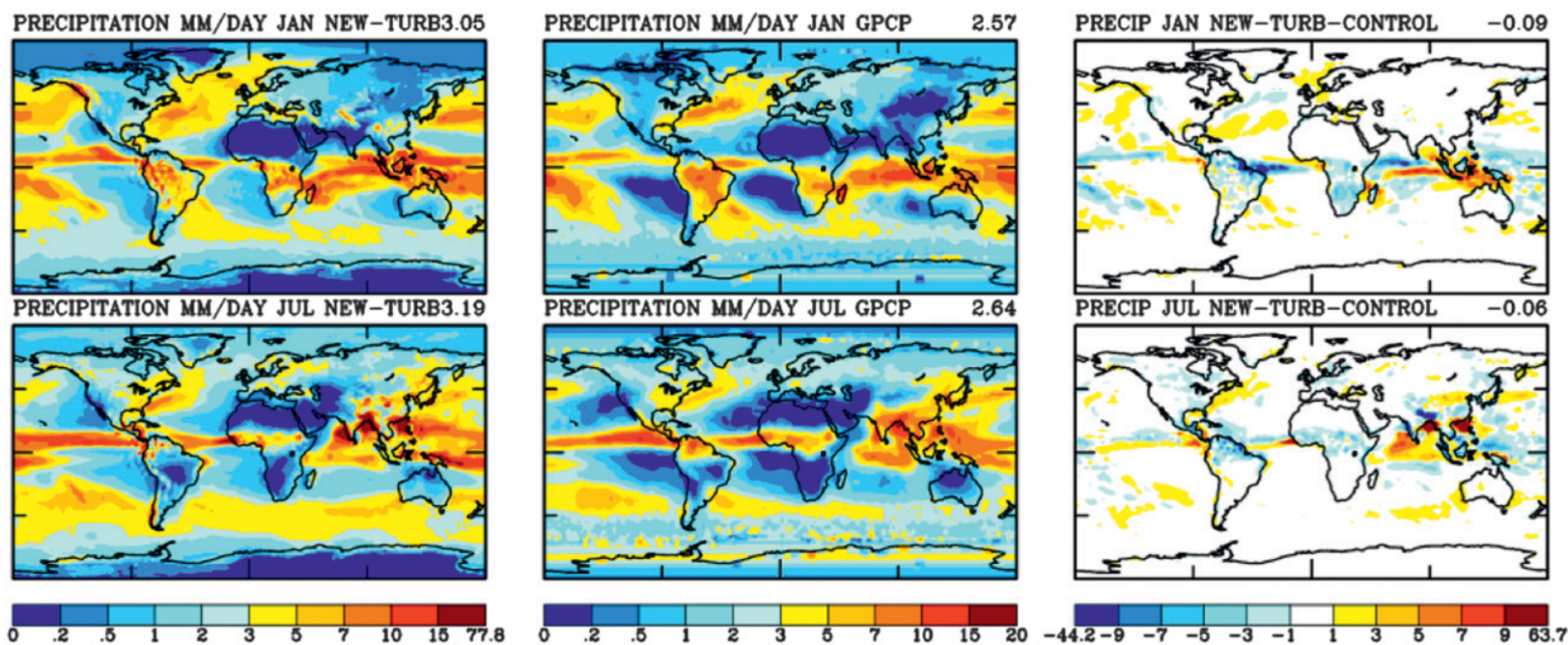

FIG. 9. Precipitation ( $\mathrm{mm} \mathrm{day}^{-1}$ ) of NEW-TURB, GPCP observation, and NEW-TURB-CONTROL for (top) January and (bottom) July. 
parameterization, the $\mathrm{RH}$ and the low cloud cover peak unrealistically close to the surface; with the dry convection parameterization, these two quantities improve their vertical structures, but the vertical transport of water vapor is still weak in the PBL; with only local turbulence parameterization, the effects are similar to the case of the dry convection in the tropics; with both local and nonlocal turbulence parameterizations, the $\mathrm{RH}$ and low cloud cover have better vertical structures in the tropics due to more significant transport of water vapor in the PBL. This suggests that a cloud-producing scheme needs to be constructed in a framework that also takes turbulence into consideration.

The climatologies of cloud and radiation obtained from a newer version of turbulence parameterization are also compared with those obtained from the AR5 version. This newer version of parameterization has significant improvements in cloud and radiation simulations, especially over the subtropical eastern oceans and the southern oceans. The differences of the diagnosed PBL height between the newer version and the AR5 version appear to correlate well with the differences of the total cloud distribution over oceans.

Although this newer version of turbulence parameterization produces better simulations of cloud and radiation, its vertical transports of heat and moisture in the tropics are not as deep as in the AR5 version.

Acknowledgments. We thank A. Del Genio for critically reviewing the manuscript and for his many useful suggestions, and $\mathrm{J}$. Wu for analyzing the diurnal variations of the convective precipitation. We also thank the two anonymous reviewers for their helpful suggestions that made this manuscript possible. This study is supported by NASA's Modeling, Analysis and Prediction Program.

\section{REFERENCES}

Bony, S., and J.-L. Dufresne, 2005: Marine boundary layer clouds at the heart of tropical cloud feedback uncertainties in climate models. Geophys. Res. Lett., 32, L20806, doi:10.1029/ 2005GL023851.

Bretherton, C. S., and S. Park, 2009: A new moist turbulence parameterization in the Community Atmosphere Model. J. Climate, 22, 3422-3448.

Cess, R. D., and Coauthors, 1990: Intercomparison and interpretation of climate feedback processes in 19 atmospheric general circulation models. J. Geophys. Res., 95 (D10), 16 601-16 615.

Cheng, Y., V. M. Canuto, and A. M. Howard, 2002: An improved model for the turbulent PBL. J. Atmos. Sci., 59, $1550-1565$.

Del Genio, A. D., M.-S. Yao, W. Kovari, and K. K.-W. Lo, 1996: A prognostic cloud water parameterization for global climate models. J. Climate, 9, 270-304.
,-- , and J. Jonas, 2007: Will moist convection be stronger in a warmer climate? Geophys. Res. Lett., 34, L16703, doi:10.1029/ 2007GL030525.

Grenier, H., and C. S. Bretherton, 2001: A moist PBL parameterization for larger-scale models and its application to subtropical cloud-topped marine boundary layers. Mon. Wea. Rev., 129, 357-377.

Hannay, C., D. L. Williamson, J. J. Hack, J. T. Kiehl, J. G. Olson, S. A. Klein, C. S. Bretherton, and M. Köhler, 2009: Evaluation of forecasted southeast Pacific stratocumulus in the NCAR, GFDL, and ECMWF models. J. Climate, 22, 2871-2889.

Hansen, J. E., G. L. Russell, D. Rind, P. Stone, A. Lacis, R. Ruedy, and L. Travis, 1983: Efficient three-dimensional models for climate studies. Mon. Wea. Rev., 111, 609-662.

Holtslag, A. A. M., and C.-H. Moeng, 1991: Eddy diffusivity and countergradient transport in the convective atmospheric boundary layer. J. Atmos. Sci., 48, 1690-1700.

, and B. A. Boville, 1993: Local versus nonlocal boundarylayer diffusion in a global climate model. J. Climate, 6, 18251842.

Huffman, G. J., and Coauthors, 1997: The Global Precipitation Climatology Project (GPCP) combined precipitation dataset. Bull. Amer. Meteor. Soc., 78, 5-20.

Kärcher, B., and U. Lohmann, 2002: A parameterization of cirrus cloud formation: Homogeneous freezing of supercooled aerosols. J. Geophys. Res., 107, 4010, doi:10.1029/ 2001JD000470

Large, W. G., J. C. McWilliams, and S. C. Doney, 1994: Oceanic vertical mixing: A review and a model with a nonlocal boundary layer parameterization. Rev. Geophys., 32, 363403

Lock, A. P., A. R. Brown, M. R. Bush, G. M. Martin, and R. N. B. Smith, 2000: A new boundary layer mixing scheme. Part I: Scheme description and single-column model tests. Mon. Wea. Rev., 128, 3187-3199.

Mellor, G. L., and T. Yamada, 1982: Development of a turbulence closure model for geophysical fluid problems. Rev. Geophys. Space Phys., 20, 851-875.

Moeng, C.-H., and P. P. Sullivan, 1994: A comparison of shear- and buoyancy-driven planetary boundary layer flows. J. Atmos. Sci., 51, 999-1022.

Nakanishi, M., 2001: Improvement of the Mellor-Yamada turbulence closure model based on large-eddy simulation data. Bound.-Layer Meteor., 99, 349-378.

Park, S., and C. S. Bretherton, 2009: The University of Washington shallow convection and moist turbulent schemes and their impact on climate simulations with the Community Atmosphere Model. J. Climate, 22, 3449-3469.

Rayner, N. A., D. E. Parker, E. B. Horton, C. K. Folland, L. V. Alexander, D. P. Rowell, E. C. Kent, and A. Kaplan, 2003: Global analyses of sea surface temperature, sea ice, and night marine air temperature since the late nineteenth century. J. Geophys. Res., 108, 4407, doi:10.1029/2002JD002670.

Rio, C., F. Hourdin, J.-Y. Grandpeix, and J.-P. Lafore, 2009: Shifting the diurnal cycle of parameterized deep convection over land. Geophys. Res. Lett., 36, L07809, doi:10.1029/ 2008GL036779.

Rossow, W. B., C. Delo, and B. Cairns, 2002: Implications of the observed mesoscale variations of clouds for the earth's radiation budget. J. Climate, 15, 557-585.

Schmidt, G. A., and Coauthors, 2006: Present-day atmospheric simulations using GISS ModelE: Comparison to in situ, satellite, and reanalysis data. J. Climate, 19, 153-192. 
Siebesma, A. P., and Coauthors, 2003: A large eddy simulation intercomparison study of shallow cumulus convection. J. Atmos. Sci., 60, 1201-1219.

Tiedtke, M., W. A. Hackley, and J. Slingo, 1988: Tropical forecasting at ECMWF: The influence of physical parameterization on the mean structure of forecasts and analyses. Quart. J. Roy. Meteor. Soc., 114, 639-664.

Trenberth, K., and J. T. Fasullo, 2010: Simulation of present-day and twenty-first-century energy budgets of the southern oceans. J. Climate, 23, 440-454.
Troen, I. B., and L. Mahrt, 1986: A simple model of the atmospheric boundary layer; sensitivity to surface evaporation. Bound.-Layer Meteor., 37, 129-148.

Weare, B. C., I. I. Mokhov, and Project Members, 1995: Evaluation of total cloudiness and its variability in the Atmospheric Model Intercomparison Project. J. Climate, 8, 2224-2238.

Yao, M.-S., and A. D. Del Genio, 1999: Effects of cloud parameterization on the simulation of climate changes in the GISS GCM. J. Climate, 12, 761-779. 